International Journal of Forensic Science \& Pathology (IJFP)

ISSN 2332-287X

\title{
A Study of Stab wounds in Sexual Homicides
}

\section{Dinesh $\mathrm{RaO}^{1 \& 2}$}

${ }^{1}$ Department of Forensic Medicine. SIMS.No 15, Bangalore-90. India.

${ }^{2}$ Ex-Director and Chief Forensic Pathologist.Kingston.

\begin{abstract}
In the present a total of 236 of stab wound Homicides were studied of which 86 were Sexual Homicides and 150 were Nonsexual Homicides. The Gender distribution had contrasting findings, in Sexual Homicides the Male to Female ratio was 1:4 whereas in Nonsexual victims the ratio was 14:1. The major age group involved in Sexual homicides were 21-30yrs whereas the Majority of the victims of Nonsexual homicides belonged to age group 21-40yrs. The sexual homicides never affected victims belonging to the first and 5th decade. Single edged stab wounds were commonly found in Stab wounds. Each of the Sexual Homicides victim sustained a minimum of Ten Stab Wound ,the maximum noted were 41-50 stab wounds in $9.3 \%[\mathrm{n} 8]$ of victims, highest number of victims[n-58;67.4\%] sustained $21-30$ stab wound. $50.67 \%$ [n-76] of victims of non sexual homicides sustained 2-3 stab wound and $17.3 \%$ [n-26] of the victims sustained single Fatal Stab wound. The Genitals were affected in 30\% [n-26] of Sexual Homicides. However in 74.67\% [n-112] of the Victims of Non Sexual Homicides chest was affected. In Sexual homicides the Head and neck were involved in all cases. The Morphology of Stab wound in Sexual Homicides demonstrated a varied wound track pattern with extensive tailing of the wound and overlapping of the stab at places besides this ,Majority of the Stabs were superficial or Non fatal in Nature an observation differentiating from the Nonsexual Victims. Majority of the Victims of Sexual Homicide demonstrated multiple superficial linear incised wounds over the body. In Sexual Homicides circumstances, Crime Scene Evidence, Autopsy evidence and Perpetrators personality analysis is essential to conclude Sex Relation to the Victim.
\end{abstract}

Keywords: Sexual; Nonsexual; Sexual Sadism; Sexual Deviation; Perpetrator; Stabbings.

\section{*Corresponding Author:}

\section{Dinesh Rao MBBS.DFM.,MD.,DNBFM,}

Department of Forensic Medicine. SIMS.No 15, Bangalore-90. India.

E-mail: dineshrao22@yahoo.com

Recieved: November 07, 2014

Accepted: November 22, 2014

Published: December 10, 2014

Citation: Dinesh Rao (2014) A Study of Stab wounds in Sexual Homicides. Int J Forensic Sci Pathol. 2(9), 70-76. doi: http://dx.doi. org/10.19070/2332-287X-1400019

Copyright: Dinesh Rao $^{\circ} 2014$. This is an open-access article distributed under the terms of the Creative Commons Attribution License, which permits unrestricted use, distribution and reproduction in any medium, provided the original author and source are credited.

\section{Introduction}

Sex related homicides are the result of Interpersonal violence oriented disputes and assaults, Rape/Sodomy and Lustmurder but majority of the cases do occur in non-paraphilic person's emotional challenges. Sexual sadism refers to the derivation of sexual pleasure from the infliction of pain, suffering and/or humiliation upon another person. The pain and suffering of the victim, which may be both physical and psychological, is pivotal to the sexual arousal and pleasure. The ICD-10 (World Health Organization, 1992) [1] defines sadism as "preference for sexual activity that involves bondage or infliction of pain or humiliation."

The sex drive is normally sufficiently powerful enough to override all but the most severe social sanctions. Thus we see variant sexual needs frequently erupting into variant sexual behaviors [2]. sexual deviations are acts which involve non-consent or assault and those acts which can be described as problematic from the standpoint of welfare of the society [2].Geberth VJ[1993] [3] classified sex-related homicides into four distinct categories based upon frequency of occurrence.

1. Interpersonal violence oriented disputes and assaults. These $\mathrm{d}$ isputes involve husbands and wives, men and women, boy and girl friends and sometimes siblings (incestuous homicides). Sometimes love triangles may also be seen. The motive is such murders is hate anger, jealousy or revenge with the thought that "If I cannot have you, no one else can too" Depersonalization is a notable feature of such murders.

\section{Rape and/or sodomy oriented assault.}

3. Deviant oriented assault commonly referred to as a lust murder or psychotic killing (in these situations the motive for the murder is not readily discernible.) "The Lust murder" This type of sex murder is committed by someone defined as a lust murderer who is oriented towards deviant and sexually sadistic assault and is easily differentiated from other types of sex-murderers by extensive mutilation of the body. 
4. The serial murder is defined as the killing of 3 or more separate victims with emotional time.

Breaks between the killings. In psychiatric terminology, a serial killer may be defined as either psychotic or psychopathic depending upon the information supplied during the examination.

There are many methods employed in executing the Murder in such cases, however the commonest method observed is multiple stabbing, the pattern and distribution of stabs in this cases were different from those due to other Stabbing incidents. This study establishes a close connection with Sexual intent/crime and the pattern and distribution of stabbing. This study was both a prospective and retrospective study of 236 cases of Homicides due to stabbing during a period of Six years. The cases were analyzed according to the motive of the homicide, as well as by method, age, and gender of the victim, and the relationship between the victim and the assailant. The homicides were divided into nonsexual and sexual based on their motives. Sexual Homicides are those wherein the Motives included rape, jealousy, Extramarital Affairs, Sexual deviation, Sexual Sadism [4,5], paraphilia, and disturbed emotional relationships between the victim and the assailant besides the presence of evidence of sexual activity observed at the crime scene or upon the body of the victim. It included both Homosexual and Heterosexual relationships.

\section{Aims and Objectives}

- To Study the Age and Sex Differentiation in Stab Wound Victims

- To Differentiate the Sexual and Nonsexual Homicides due to Stab Wound.

- To study the Type of wound/Weapon used in Stab wound Homicides.

- To study the Distribution of Stab wounds on the body in Sexual and Nonsexual Victims.

- To study the total number of stab wounds on the bodies of Homicidal victims due to Stabbing.

- To study the Morphology pattern of Stab wounds in Sexual and Nonsexual Victims.

- To study the Characters of Sexual and Nonsexual Homicides.

\section{Material and Methods}

- The study conducted from 2007 to 2012. 2007 to 2008 [two years] retrospective study and 2009-2012[four years] prospec tive study.

- A total of 5619 Homicides reported of which 236 were Homi cides due to Stab wounds.

- Of the 236 Stab wound Homicides,86 were due to Sexual Hom icides and 150 cases due to Non Sexual Homicide.

- Sexual Homicides were the results of Motives of rape, jealousy, Extramarital Affairs, Sexual deviation, Sexual Sadism, paraphilia, and disturbed emotional relationships between the victim and the assailant besides the presence of evidence of sexual activity observed at the crime scene or upon the body of the victim. All other Stab Wound Homicides were designated as Nonsexual.

- The cases were analysed based on the motive, age, and gender of the victim, and the relationship between the victim and the as sailant, Morphology of Stab wound and number of stab wounds. - It included both Homosexual and Heterosexual relationships.
- All the Stabbing Victims were brought for the Medico legal Post-mortem Examination.

- The body was externally examined and Stab wounds were described in relation to Distribution, Size, Shape, Direction of Track, Tailing, Overlapping, Margins, Depth and Bevelling.

- Weapons recovered from the Investigating Officer/Crime Scene Officers were studied and compared with the Injury pre sent on the body.

- The Accused motive was analyzed based on his statement, in vestigative findings, Technical details [phone, emails], relation ship, Intimate details like togetherness, dependency, socialisa tion, makeover, disputes, sexual encounters, crisis through the Accused, witness and friends of the deceased and accused by the Investigating Officer. This Investigative Findings were con sidered to categorise the cases.

- Dissection Technique of enmasse removal of Organs done in all Autopsies, the depth and Direction of the wound were stud ied during this process.

\section{Results}

1. A total of 236 cases were studied of which the Total Sexual Victims were 86 and the Total Nonsexual victims were 150 . The Male to Female Ratio in Sexual homicides is 1:4 and 68 of the victims [79\%] are Females. The Male to female Ratio in Non Sexual Victims is $14: 1.139$ of the Victims [92.6\%] are Males.

2. A total of 57 [66.3\%] of the Sexual Homicide Victims belonged to $21-30 \mathrm{yrs}$ age group and none below the age of $10 \mathrm{yrs}$ and above the age of 50yrs. Majority of the Nonsexual Homicide Victims belonged to the age group 21-30yrs and 31-40yrs contributing to $32 \%[\mathrm{n}-48]$ and $28 \%[\mathrm{n}-42 \%]$ respectively. Nonsexual Homicide victims below $10 y e a r s$ contributed to $4.7 \%$ [n-7] and above $50 \mathrm{yrs}$ contributed to $10.7 \%$ [n-16].

3. The commonest type of stab wound [weapon] in Stabbing Homicides were Single sharp Edged wound in187 [79.2\%] of the Victims of which $42 \%$ [n-79] of the Victims belonged to Sexual Homicides and 108[58\%] of Non Sexual Homicides. Penknives in $30.2 \%$ [n-26] and Kitchen Knives were preferred in 22.1\% [n-19] of the Sexual homicide victims. In Nonsexual Victims, 25.3\% [n$38]$ of the wounds had Double sharp edges, The Kitchen knives were used in only $5.3 \%$ [n-8] of the victims.

4. All Sexual Homicides victims had a minimum of Ten Stab Wounds the maximum number of stabs noted were $41-50$, in $9.3 \%$ [n- 8 ] of the victims. In $67.4 \%$ of victims [n-58; $21-30$ stab wounds were noted. None of the Nonsexual Homicide victims sustained more than ten stab wounds. In $50.7 \%$ [n-76] of the Victims the maximum number of stab noticed was three. In $17.3 \%$ [n-26] of victims sustained one fatal stab wound on the body. Only $10 \%$ [n-15] of the victims sustained 6-10 stab wounds and $22 \%$ [n-33] of the victims sustained $4-5$ stab wounds.

5. All the sexual Homicide victims [n-86] Neck and Head were affected. Genitals were affected in 30\% [n-26] of Sexual Homicides. In 34 victims [22.7\%] chest was affected. Abdomen in $9.3 \%$ [n-14] of the sexual homicide victims. The back was involved in $16 \%$ [n-24] of the victims. In all Nonsexual Homicide victims the genitals were unaffected and in $74.67 \%$ [n-112] of the Victims chest were affected and abdomen was affected in 32\% [n-48] of the victims. The Face and neck (Figure 1,2,3,4,5) were affected in $2.7 \%[\mathrm{n}-4]$ and $12 \%[\mathrm{n}-18]$ respectively. Back was affected in $8 \%$ 
[n-12] of the victims.

6. The Sexual Homicides demonstrated a varied wound track pattern with extensive tailing of the wound and overlapping of the stab at places besides this, Majority of the Stabs were superficial or Non fatal in Nature. Multiple Linear Superficial Incised Wounds seen across the body in majority of Sexual Homicide victim. All the Stabs in Nonsexual Victims were deep in nature. In Nonsexual homicide victims, none of the stab wounds demonstrated tailing or overlapping and all the stab wounds track had a well defined wound direction.

\section{Discussion}

Sexually Driven Homicides is not uncommon in the Society, Though Sexually driven Homicides are commonly found in the
Sexual deviated/Sadistic individuals [4,5], it is not uncommon in Non paraphiliac individuals and these homicides are committed due to a dominating Emotional factor. The end result of expression of high end Emotions and Sexual deviation/sadism has resulted in inflicting extreme degree of pain and suffering in the form of multiple Stabbing, the object of this study. The study included both Homosexual and Heterosexual Relationships. The Sexual Homicides were differentiated from Nonsexual Homicides based on the following Circumstances, Characters of the Perpetrators and Evidences.

1. Sexually driven factors [3]:

a. Interpersonal Violence Oriented disputes and Assaults like Extra marital Affairs, Live in Relationship, Infidelity, Rape, jealousy,

Table 1. Sex Distribution

\begin{tabular}{|c|c|c|}
\hline Sex & Sexual & Nonsexual \\
\hline males & 18 & 139 \\
\hline females & 68 & 11 \\
\hline Total & 86 & 150 \\
\hline
\end{tabular}

Table 2. Age Distribution

\begin{tabular}{|c|c|c|}
\hline Age & Sexual & Nonsexual \\
\hline$<10$ & 0 & 7 \\
\hline $20-$ Nov & 04 & 14 \\
\hline $21-30$ & 57 & 48 \\
\hline $31-40$ & 19 & 42 \\
\hline $41-50$ & 6 & 23 \\
\hline $51-60$ & 0 & 16 \\
\hline
\end{tabular}

Table 3. Type Of Stab Wound[Weapon]

\begin{tabular}{|c|c|c|c|c|}
\hline S1 no & Weapon type & Single edged wound & Double edged wound & $\begin{array}{c}\text { Irregu- } \\
\text { lar }\end{array}$ \\
\hline 1 & Sexual & $\begin{array}{c}79 \\
\text { Penknives } 26[30.2 \%] \\
\text { Kitchen knives-19[22.1\%] }\end{array}$ & $06[6.98 \%]$ & $1[1.2 \%]$ \\
\hline 2 & Nonsexual & $\begin{array}{c}108 \\
\text { Penknives-3 }[2 \%] \\
\text { Kitchen knives-8[5.3\%] }\end{array}$ & $38[25.3 \%]$ & $4[2.7 \%]$ \\
\hline 3 & Total & $187[79.2 \%]$ & $44[18.6 \%]$ & $5[2.1 \%]$ \\
\hline
\end{tabular}

Table 4. Total Number Of Stab Wounds On The Body

\begin{tabular}{|c|c|c|}
\hline Total Number & Sexual & Nonsexual \\
\hline 1 & 00 & 26 \\
\hline $2-3$ & 00 & 76 \\
\hline $4-5$ & 00 & 33 \\
\hline $6-10$ & 00 & 15 \\
\hline $11-20$ & 08 & 00 \\
\hline $21-30$ & 58 & 00 \\
\hline $31-40$ & 12 & 00 \\
\hline $41-50$ & 08 & 00 \\
\hline
\end{tabular}


Table 5. Distribution Of Stab Wounds

\begin{tabular}{|c|c|c|}
\hline Anatomical Sites & Sexual & Nonsexual \\
\hline Head & 86 & 4 \\
\hline neck & 86 & 18 \\
\hline chest & 34 & 112 \\
\hline abdomen & 14 & 48 \\
\hline Upper limbs & 12 & 39 \\
\hline Lower limbs & 8 & 27 \\
\hline Buttocks & 8 & 2 \\
\hline Back & 24 & 12 \\
\hline genitals & 26 & 0 \\
\hline
\end{tabular}

Table 6. Morphology Of Stab Wounds

\begin{tabular}{|c|c|c|}
\hline Morphology & Sexual & Nonsexual \\
\hline Margins & Clean cut & Clean cut and contused Margins \\
\hline Superficial & Majority & Nil \\
\hline Deep & Few & All \\
\hline Wound Direction/track & Undefined/Varied & Nil \\
\hline Tailing & Extensive & Present \\
\hline Beveling & Present & Nil \\
\hline Overlapping & Present & Nil \\
\hline Multiple Linear Superficial Incised wounds & Majority & \\
\hline
\end{tabular}

Sexual perversions, paraphilia, Failed Affair and disturbed emotional relationships between the victim and the assailant.

b. Rape and/or Sodomy oriented Assault.

c. Sexual Deviation referred to as Lust Murder or Psychotic Killing.

2. The Personality of the Offender, his Psychology [2].

3. Crime Scene Evidence like Porn material, explicit writings, semen, nude body etc.

4. Physical Evidence during Autopsy-Injury to genitals, Genital injury recent and old, STDs etc.

5. Microscopic Evidence like Semen, Vaginal epithelial cells, DNA evidence, Saliva, Nail scrapings, Stains etc.

6. Criminal recidivism of the Perpetrators [6].

The circumstances, Personality and sexually driven factor information was provided by the Homicidal detectives, Family physician and Family members through the Investigators. In this study the Male to Female Ratio in Sexual Homicides was 1:4 and 68 of the victims $[79 \%$ ] were Females and observation Contrary to the Non Sexual Stabbing Homicides wherein the Male to female Ratio was 14:1, 139 of the Victims [92.6\%] were Males. The results confirm the vulnerability of the Females in Sex related Murders and the nonsexual ratio is close to the observation made by Miata. A. [2013] [7]. The Majority of the Stabbing victims belonged to the 3 and 4 th decade of life an observations similar to those made by Muataz.A. [2013] [7] and Kemal CJ [2013] [8]. The Majority [n-187;79.2\%] of Stabbing wounds had a single sharp cutting edge, similar were the observations of Muataz. A [2013] [7]. The Head, Neck were most preferred sites [100\%] in Sex related Homicides whereas Chest was preferred in $75 \%$ cases of Non Sexual Homicides, a similar view shared by Muataz. A.[2013] [7].
Figure $(1,2,3,4,5)$ Involvement of Genitals was seen in 30\% of Sex Related Homicides, whereas Genitals were never affected in Non Sexual Homicides. Hence Distribution pattern of Stab Wounds is important to understand the possible Motive behind the Stabbing. The number of Stab wounds is an important criterion unique to Sex related homicides. in the present Study confirmed multiple stabbing as an important character of Sex Related homicides, the study indicated that each of the 86 sex related homicides had sustained a minimum of Ten Stabs and Maximum stab wounds recorded were between $41-50$ in $9.3 \%$ of cases[n-8] and Majority of Sex related homicide Victims i.e. in $67.4 \%$ [n-58] of cases the total number of stabs recorded were between 21-30 stabs, similar were the views of Radojevic.N.[2013] [9].In non sexual Homicides none of the Victims recorded more than 10 stab wounds and $51 \%$ of the victims recorded $2-3$ stab wounds and $17.3 \%$ of the victims sustained single Fatal Stab wounds. Hence the total number of Stab wound is an important criteria besides other criteria discussed above to differentiate Sexual from Nonsexual Homicides due to stabbing. The study of morphology of the Stab wounds is another important part of this study. It was noted that majority of Stab wounds in Sexual Homicides showed Extensive Tailing, Overlapping and the Direction of the Wound Varied and did not Satisfy to a single pattern whereas in Nonsexual Homicides Stab wounds demonstrated Absence of Tailing or Overlapping and all the Stab wounds had a well defined direction. The Majority of sexual homicide victims demonstrated Multiple Superficial linear incised wounds ,a finding never seen in Nonsexual Homicides. The presence of Tailing, overlapping and wounds of varied direction is possibly due to the victim being stabbed in an Acute angle, movement of the Victims warding the stab, an attempt to twist and rock the weapon $[9,10,11]$ beside this it reflects the highly charged emotional state of the assailant and the Victim. 
Figure 1. Showing Multiple Stabs and Superficial Incised Wound involving Face and Neck

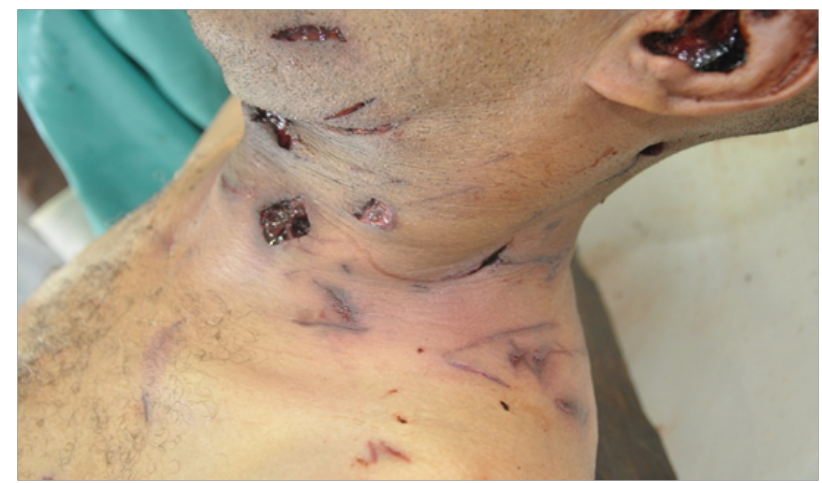

Figure 2. Showing Multiple Stab wound involving Neck

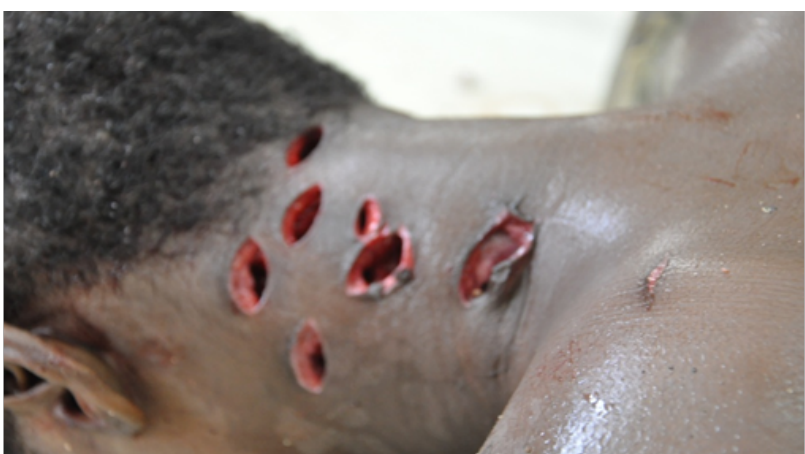

Figure 3. Showing Multiple Stabs and Superficial Incised Wound involving Neck

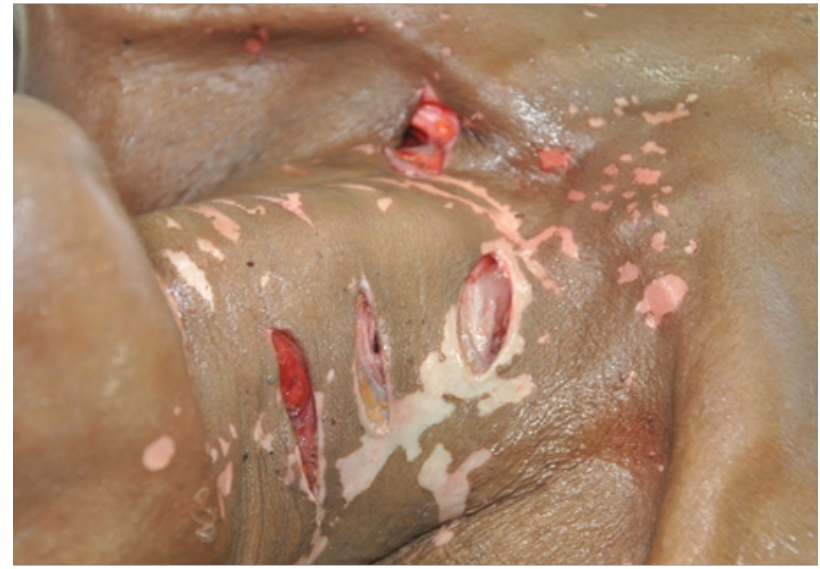

Figure 4. Showing Multiple Stabs and Superficial Incised Wound Involving Neck

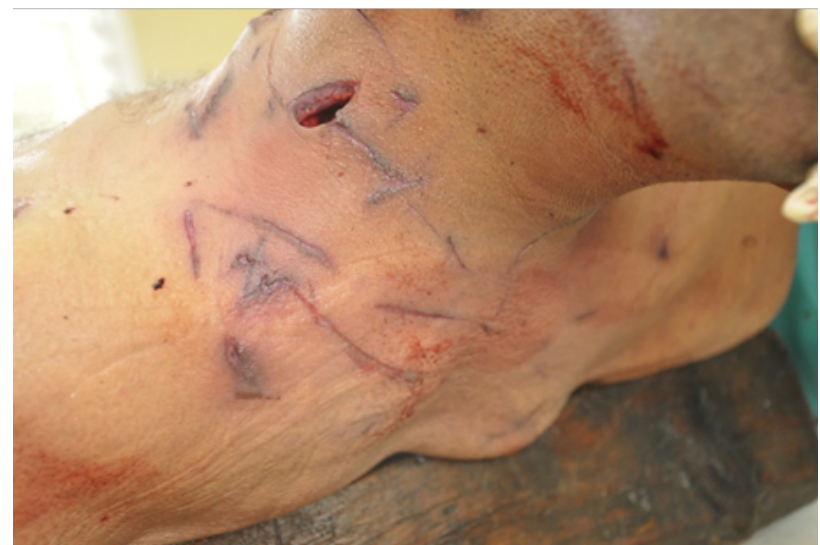


Figure 5. Showing Single Fatal Stab wound to Chest

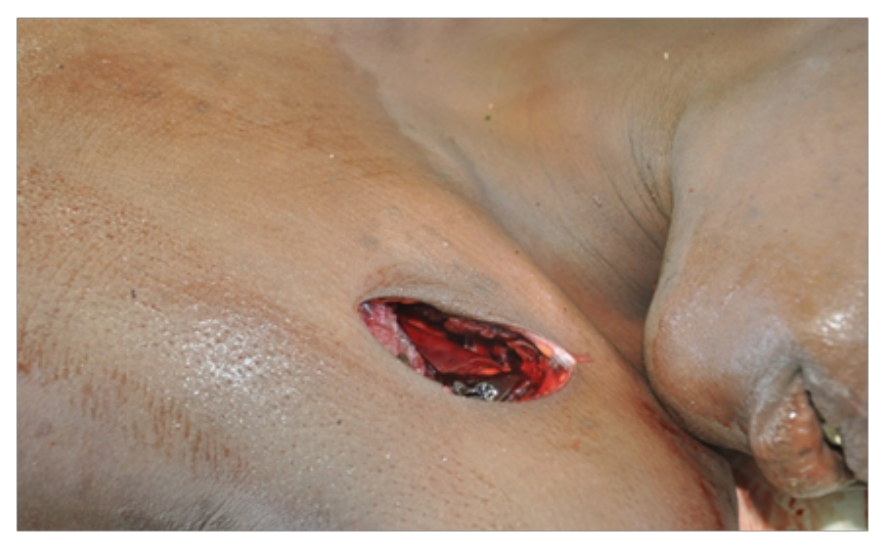

The majority of the Sexual Homicides stabs were superficial and few were fatal. The present study highlighted the Morphological pattern of Stab wounds, and its Distribution of stab beside the Number of stab wounds that characterises Stab wounds in Sexual Homicides, hence adding up to the unique nature of the work as compared to similar studies done elsewhere[Radojevic.N.[2013] [12]. and H.sing [2005] [13]. The increased number of Stab wounds and extensive tailing and overlapping affecting Head, Face and Genital in Sexual Homicides reflects the Affect 3,pattern of the non paraphiliac individual, the sexual deviation or sexual sadistic nature of the Perpetrator which is not seen in Nonsexual Homicides [14-17]. Hence in all cases of Stabbing Homicides the study of Morphology, number, Distribution pattern, Type of Stab, and the Sex group affected is important to differentiate the Sexual and Nonsexual Homicides besides studying the Circumstances, Characters of the Perpetrators and Evidence materials.

\section{Conclusions}

- Crime scene Examination of Sexual homicide victims is essen- tial to understand the Sexual affiliations of the Victims and Perpetrator.

- Autopsy evidence of Genitals and Anus is essential to understand the Sexual affiliations and the Offence. Figure 6(a,b).

- Evidence collected from the Crime scene and Body[semen, blood stain, clothes, hair, condom, porn material] is essential to establish sexual homicides.

- The study of the Nature and Circumstances of the Homicide and the Perpetrator in relation to his Interpersonal behaviour, Psychology, Sexual deviation and Emotion is necessary.

- Sexual homicide victims recorded more than Ten Stabbing and majority recorded 21-30stabbing.

- The Head, Neck were the common site affected in Sexual homicides.

- The genitals were never involved in Non Sexual Homicides.

- The Stab wounds in Sexual Homicides Showed Extensive Tailing, overlapping and majority of them were Superficial in nature. Figure 6c.

- Single edged Stab wounds were the common type of Wounds recorded in Homicide due to Stabbings.

- Majority of the Victims are Females in Sexual Homicides. Figure

Figure 6 a,b

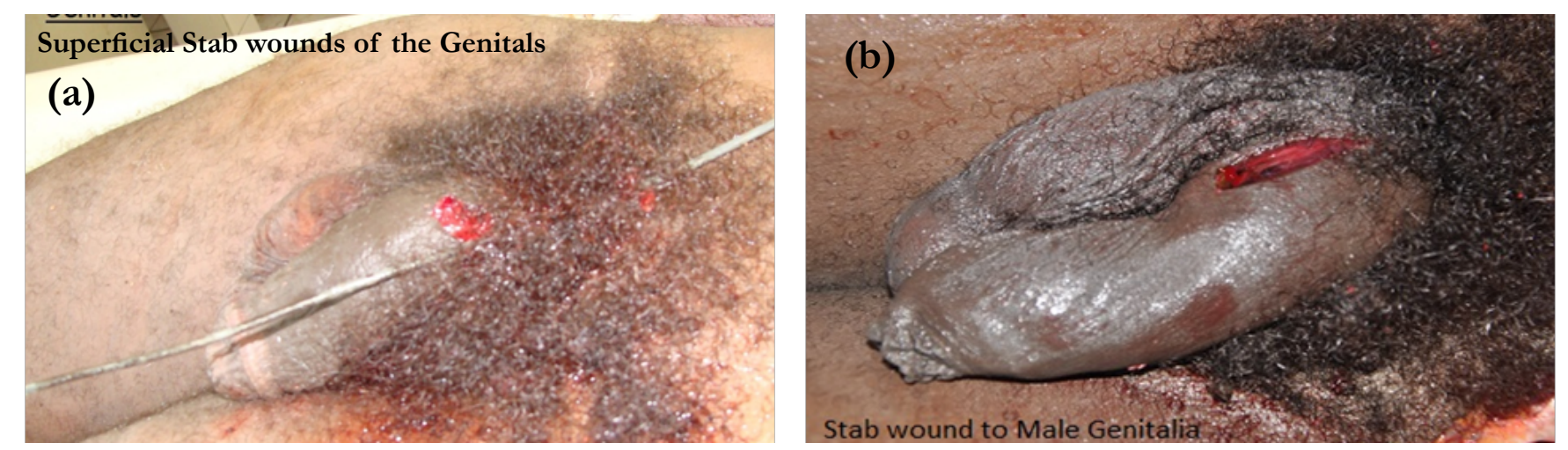

Figure $6 \mathrm{c}$

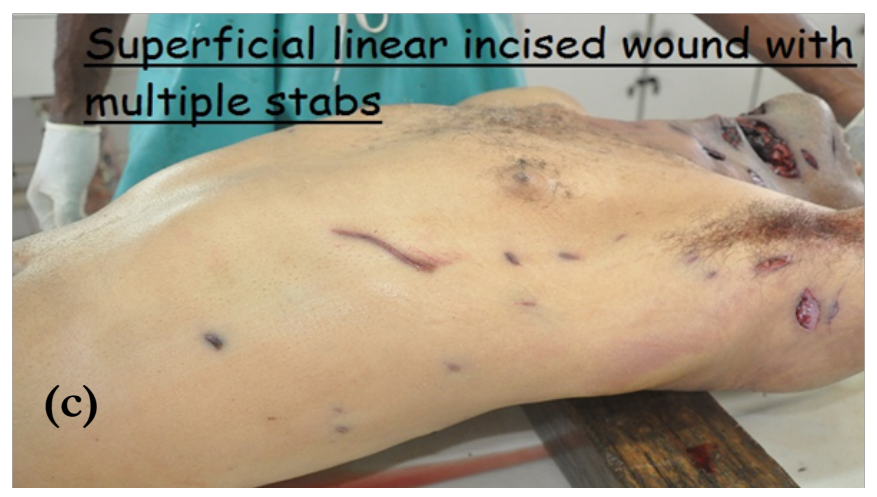


Figure 6 d

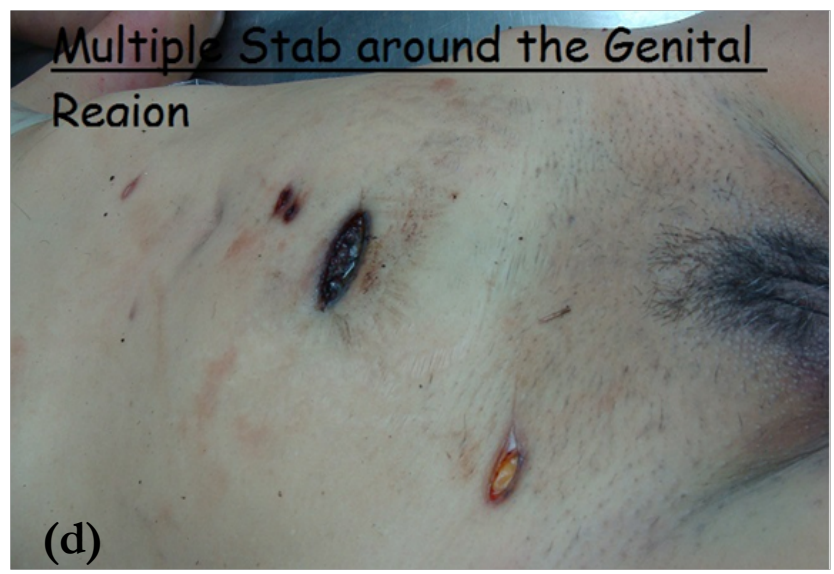

6d.

\section{References}

[1]. ICD-10 (World Health Organization, 1992).

[2]. Coleman JC, Butcher IN, Corson RC, (1984).Abnormal psychology and modern life. (7th edtn), Texas: Scott Freshman and Co. 457

[3]. Geberth VJ, (1993) The investigation of sex related homicides. In: Practical Homicide Investigation tactics, procedures and Forensic Techniques, (2nd Edition), CRS Press Boca Raton, USA; 295-330.

[4]. Yates P, Hucker S.J., Kingston D, (2008) "Sexual sadism: Theory and Psychopathology”. In: Sexual Deviance: Theory, Assessment \& Treatment, (2nd Edition). Laws, R. \& O’Donohue, W. (eds). Guilford Press.

[5]. Hucker, S.J . (2009) "Manifestations of Sexual Sadism: Sexual Homicide, Sadistic Rape and Necrophilia”. In: Sexual Offenders. Saleh, F., Bradford, J., Brodsky, D. (eds). Oxford University Press.

[6]. Hill A, Habermann N, Berner W, Briken. P, (2006) Sexual Sadism and Sadistic Personality disorder in Sexual homicide. J Pers Disord Dec.20(6): 671-84

[7]. Muataz A, Al-Qazzaz, Zaid Ali Abbas, (2013) Medico-Legal Study of Fatal Wounds in Bagdad. The Iraqi Postgraduate Medical Journal 12(1).
[8]. Kemal CJ, Patterson T, Molina DK, (2013) Deaths due to Sharp Force Injuries in Bexar County,with respect to manner of Death. Am J Forensic Med PAthol. Sep; 34(3);253-9.

[9]. Hunt A.C. (2003), 'Morphology of knife wounds', Presentation to the British Association in Forensic Medicine Winter Meeting, Cardiff, Wales.

[10]. Horsfall I., Prosser P.D., Watson C.H., Champion S.M. (1999), An assessment of human performance in stabbing', Forensic Science International 102: 79-89.

[11]. Hunt A.C., Cowling R.J. (1991), 'Murder by stabbing', Forensic Science International, 52:107-112.

[12]. Radjevic N, Radnic B, Petkovic S, Miljen M, Curovic L, et al,(2013) Multiple Stabbing in Sex related Homicides. J Forensic Leg Med.Jul 20(5);502-7.

[13]. H. Singh, L. Sharma, S. K. Dhattarwal, (2005) Sex related Homicides and Offenders-A Medico Legalists View. JIAFM, 27 (3).

[14]. MacCulloch, M., Snowden,P., Wood,P. \& Mills, H. (1983). Sadistic fantasy, sadistic behavior, and offending. British Journal of Psychiatry, 143: 20-29.

[15]. McGuire, R.J., Carlisle, J.M., \& Young, B.G. (1965). Sexual deviation as a conditioned behavior: A hypothesis. Behavioral Research and Therapy, 2, 185-190.

[16]. Karpman, B. (1954). The sexual offender and his offenses: Etiology, pathology, psychodynamics and treatment. New York: Julian Press.

[17]. Krafft-Ebing, R. von. (1965). Psychopathia sexualis. New York: Stein \& Day. 